\title{
RESGATE DE VALORES: FÁBULAS E OUTRAS DiNÂMICAS*
}

\section{Redemption of values: fables and other dynamics}

\author{
Glória Maria A. F. Cristofolini** \\ Daniela da Silva*t*
}

\begin{abstract}
RESUMO
O convívio escolar é por excelência um espaço de construção e resgate de valores humanos. A escola assume para isso um grande desafio: utilizar temas polêmicos, que instiguem o aluno à reflexão sobre os problemas inseridos na sociedade e sua resolução. Um instrumento facilitador no resgate de valores humanos é a contação de fábulas. As fábulas e outras dinâmicas motivadoras despertam o interesse e a atenção das crianças, por meio de seus personagens fictícios como animais, pessoas ou seres inanimados, apresentam uma lição de moral e facilitam a compreensão de certos valores de conduta humana ou convívio social. Este projeto pretende implantar, através de dinâmicas variadas dando ênfase à expressividade nas fábulas, a incorporação gradativa de valores humanos na educação de crianças de Educação Infantil e Séries Iniciais do Ensino Fundamental.
\end{abstract}

Palavras-chave: Cidadania; educação; escola; valores humanos.

\begin{abstract}
The coexistence in schools is mainly a space of construction and rescue of human values. Schools take it as a big challenge, using controversial issues, which motivate students to reflect on the problems inserted in society and their solution. Narration of fables is a facilitating instrument in the rescue of human values. Fables wake up the interest and the children's attention through their fictitious characters as animals, people or objects, they present a morals lesson and they facilitate the understanding of some human conduct or social living values. This project intends to implant, through narration of fables the incorporation of human values, in children's education of Infantile Education and initial grades of elementary school.
\end{abstract}

Keywords: Citizenship; education; schools; human values.

\section{RESUMEN}

La convivencia en las escuelas es, de hecho, un espacio de construcción y rescate de los valores humanos. La escuela asume por eso un gran desafío: utilizar temas polémicos, que instiguen al alumno la reflexión acerca de los problemas insertos en una sociedad y sus resoluciones. Un instrumento facilitador en el rescate de los valores humanos es el cuento de fábulas. Las fábulas y otras dinámicas motivadoras despiertan el interés y la atención de los niños, por medio de juegos en que suelen ser personajes ficticios como animales, personas o seres inanimados, presentando una lección de moral, al facilitar la elucidación de ciertos valores de la conducta humana o aún, del convivio social. Este proyecto pretende instaurar, a través de dinámicas variadas, un énfasis a la expresividad en las fábulas, bien como incorporar una gradación de los valores humanos en la educación de los niños, de la educación infantil y de las series primeras de la enseñanza fundamental.

Palabras-clave: ciudadanía; educación; escuela; valores humanos.

* Projeto de Extensão financiado pela Universidade do Vale do Itajaí / Tijucas - SC.

** Mestre em Educação - Coordenadora do Projeto - Professora da Universidade do Vale do Itajaí. E-mail: gmafc@terra.com.br.

**** Acadêmica Bolsista do curso de Pedagogia - Universidade do Vale do Itajaí / Tijucas - SC. 
Introdução

O presente artigo propõe uma reflexão acerca das atividades pedagógicas desenvolvidas como extensão universitária em que é aplicado o projeto Resgatando Valores, que se perdem na sociedade atual. Estas atividades vêm ocorrendo durante o ano letivo desde 2004, na Escola Municipal "Ondina Maria Dias", localizada na cidade de Tijucas/SC, na Escola Municipal Rodesino Pavan, em Balneário Camboriú (SC) e na Comunidade São Bom Jesus dos Passos, em São José (SC).

Acredita-se que em todas as situações da vida a criança entra em contato com os valores vigentes na sociedade, na família e na comunidade. Hoje, a televisão, a propaganda, a mídia, entre outros, veiculam ou reproduzem os valores vigentes da sociedade. E muitos desses valores não são aqueles que o bom senso ou uma educação crítica proporcionariam, supervalorizando as relações de poder e de consumo. Neste sentido, percebe-se que o resgate de valores humanos ainda hoje aparece como um dos grandes desafios do sistema educacional.

Sabe-se que as variadas dinâmicas, incluindo o ato de contar histórias, são instrumentos facilitadores no resgate dos valores perdidos, e que a escola muitas vezes despreza a riqueza destes recursos. Na prática educativa constata-se que as fábulas podem tornar-se um instrumento de desenvolvimento sócio-afetivo das crianças.

Crianças de todas as idades sentem uma atração por este tipo de texto, pois tem o poder de prender a atenção, de entreter $e$ deixar um princípio moral, um ensinamento. É justamente da tradição das fábulas que nos vem esse hábito de querer buscar uma explicação ou uma causa para as coisas que acontecem em nossa vida ou na vida dos outros, ou de tentar tirar delas algum ensinamento útil, alguma lição prática.
Todas as intervenções realizadas durante a aplicação do projeto são realizadas em escolas públicas pertencentes à rede municipal de educação de Tijucas-SC, com alunos da educação infantil e séries iniciais do ensino fundamental. Há alunos com grandes necessidades que vão além da financeira, mas também, socioafetivas, as quais precisam ser consideradas.

Muitas vezes, percebe-se que determinadas crianças já trazem, de seu ambiente familiar, princípios e valores éticos básicos, por viverem em famílias que procuram cultivar estes comportamentos em casa. Esse processo de construção e resgate dos valores não dependerá apenas do educador, mas precisa da colaboração da família, consciente de que para a formação do ser humano crítico e criativo deve-se valorizar os saberes e os valores.

Um dos objetivos principais do projeto é evidenciar a importância em se trabalhar fábula e histórias como também outras atividades lúdicas, em que o resgate e a criação de valores humanos possibilitem aos professores trocarem idéias sobre determinados valores tão necessários na comunidade e nas famílias.

Visando comprovar que, por meio da utilização das fábulas, é possível resgatar e vivenciar valores humanos, este artigo tem também como prioridade demonstrar a validade e eficiência do projeto de extensão. Quando a extensão puder adentrar aos espaços educacionais, poderá oportunizar aos educadores estarem imbuídos num trabalho conjunto, em que é possível uma educação que seja realmente a arte de conhecer, cuidar e criar. É preciso acreditar no ser integral. A criança está ligada a sua expressão natural e maneira de ser, que exigem harmonia entre corpo, mente e sentimentos. O brincar oportuniza o ser humano a expressar-se de forma natural, porém, na sua totalidade, despertando em suas crianças atitudes de valores. 


\section{A escola como ponto de partida no resgate de valores humanos}

A escola é um espaço de socialização e construção de conhecimentos e valores. Não há como adquirir conhecimento se não houver a relação entre as pessoas, se não houver a necessidade ou o desafio, ou ainda, a problematização. E é na relação humana, na interação, que os valores tornam-se relevantes.

Neste sentido, percebe-se a necessidade de a escola exercer um papel ativo e mais participativo, além de proporcionar desafios que possibilitem a construção de novos conhecimentos e de valores necessários à conquista da cidadania plena.

Assmann (2000, p. 33) adverte:

A escola não deve ser concebida como simples agência repassadora de conhecimentos prontos, mas como contexto e clima organizacional propício à iniciação em vivências personalizadas do aprender a aprender. A flexibilidade é um aspecto cada vez mais imprescindível de um conhecimento personalizado e de uma ética social e democrática.

Assim, entende-se que a escola não deve preocupar-se somente com o conhecimento por meio da absorção de informações, mas também com o processo de construção da cidadania do aluno.

Num primeiro momento, o educador pode ter uma impressão equivocada de que trabalhar com valores é simplesmente estabelecer a compreensão de valores que são adquiridos de fora para dentro, quando, na verdade, um quadro de valores é o grande arsenal interior essencial para a construção da realidade.

O professor deve ensinar para os seus alunos o que é amizade, inclusão, solidariedade, ensinar como se faz, como se vivencia, consi- derando que esse assunto é importante para viver em grupo, em sociedade. Resgatar e criar valores através de apresentações de hábitos e atitudes no cotidiano escolar para que se incorporem $e$ se transfiram ao longo da vida dos alunos.

Assim, resgata-se no aluno a sua condição de sujeito da própria aprendizagem $e$, no professor, o papel de organizador das situações que fazem o aluno avançar, desenvolver capacidades, superar limites, construir e produzir conhecimentos. Não se pode aceitar que o educador se torne apenas um repassador de conteúdos, mas que auxilie o educando a crescer e a descobrir o seu papel no mundo enquanto cidadão crítico.

Um cidadão crítico que, sobretudo, seja humano, consciente de seus valores como a solidariedade, o respeito, a amizade, a justiça, a honestidade, o diálogo, entre outros. Valores estes não ultrapassados, mas sim objetos a serem perseguidos. Portanto, todos aqueles que se comprometem com a causa de uma educação para a vida, automaticamente devem estar imbuídos de fomentar valores perdidos.

\section{Relação entre a fábula e a construção de valores}

$\mathrm{O}$ ato de contar histórias é muito apreciado pelas crianças. Acredita-se que com as fábulas é possível trabalhar os valores humanos com os alunos, conduzir as crianças não só à aprendizagem, mas permitir que o aluno compreenda os aspectos positivos e negativos que elas podem conter.

Toda fábula trata de certas atitudes humanas, como a disputa entre fortes e fracos, a esperteza, a ganância, a gratidão, o ser bondoso. Enfim, estes fatores facilitam a compreensão de certos valores pelas crianças, valores de conduta humana ou convívio social. 
Esses valores implícitos nas histórias são transmitidos para as crianças por meio de uma linguagem simbólica que pertence à história, pois na grande maioria das histórias o "bem" e o "mal" são facilmente identificados por elas.

Ouvir histórias é uma grande possibilidade de descobrir o mundo imenso dos conflitos, dos impasses, das soluções que todos vivemos $e$ atravessamos - dum jeito ou de outro - através dos problemas que vão sendo defrontados, enfrentados (ou não) resolvidos (ou não) pelas personagens de cada história (cada um a seu modo) é a cada vez ir se identificando com outra personagem (cada qual no momento que corresponde àquele que está sendo vivido pela criança) [...] (ABRAMOVICH, 2005, p.17)

Nesta perspectiva, o professor precisa estar atento ao tipo de história que pretende apresentar aos seus alunos, bem como ao tipo de leitor que quer formar. Desde cedo, é preciso formar um leitor que tenha o envolvimento integral com aquilo que lê, mas para isso, é preciso ajudá-lo a sentir liberdade e prazer ao estar lendo. Para Cagneti (2005, p.35-36), “[...] o educador vai precisar usar toda sua sensibilidade, tendo em mente que cada situação e ocasião têm aspectos muito particulares."

\section{A contação de fábulas no cotidiano da escola}

A partir da pesquisa realizada sobre a contação de fábulas como instrumento de resgate de valores humanos, foi elaborado um projeto que serviu de base teórica para a realização das atividades propostas durante a aplicação do projeto de extensão.
O projeto já citado é aplicado com crianças da Educação Infantil e Séries Iniciais da Escola de Ensino Fundamental Prof. a Ondina Maria Dias, localizada no município de Tijucas, em Santa Catarina.

As fábulas desencadeiam grande interesse dos alunos. As atividades diversificadas e contextualizadas no cotidiano escolar envolvem a contação de histórias e fazem o aluno viver novas experiências, expressar livremente seus sentimentos, pensamentos e emoções.

As fábulas são apresentadas para os alunos de forma atrativa. Segue a descrição de um momento prático:

A professora, com um avental contendo todos os personagens confeccionados de cartolina, material de fácil acesso nas escolas, contava a história de maneira que a cada momento que surgia um personagem, este era fixado no avental. As crianças ficavam atentas e ao mesmo tempo surpresas com a história.

Esta dinâmica possibilitou a concentração de todos, gerou comentários produtivos e relacionados com a própria vida, contextualizando-se em diversos momentos da apresentação. Conforme Coelho (2000, p. 31)

Os argumentos devem estimular a
imaginação, a inteligência, a afetividade,
as emoções, o pensar, o querer, o sentir...
Indiferentemente, podem se desenvolver
no mundo do maravilhoso (do Era uma
vez) ou no mundo cotidiano, dia a dia
do pequeno leitor, com suas alegrias,
desejos, travessuras, obstáculos, frustra-
ções, sonhos, etc. Ou ainda resultarem
da fusão dos dois mundos: o da Fantasia
e do Real.

Logo após as discussões, eram aplicadas dinâmicas, brincadeiras ou jogos que realmente sensibilizassem a turma.

Um exemplo bastante ilustrativo do que se acabou de afirmar foi a participação 
dos alunos na dinâmica Para quem você tira o chapéu. Iniciou-se a brincadeira com a seguinte explicação: dentro do chapéu tinha uma foto de uma pessoa muito importante. A partir daí todos os alunos ficaram curiosos para saber que foto havia dentro do chapéu.

$\mathrm{Na}$ verdade não existia nenhuma foto, era um espelho colado dentro do chapéu. Quando as crianças se aproximavam do chapéue percebiam que era um espelho, algumas ficavam tímidas porque tinham que justificar o porquê de tirar o chapéu. Houve várias justificativas surpreendentes. Entre elas destaca-se a de um aluno quando falou que tiraria o chapéu porque era bonito, legal, tímido, às vezes conversava muito na sala, mas gostava muito de fazer amigos.

Enquanto outra aluna respondeu que tiraria o chapéu porque usava roupas bonitas, tinha cabelos longos, era magra e gostava muito de ajudar as pessoas.

Estes dois educandos geralmente são os mais distraídos da sala e sempre gostam de conversar; no entanto, participaram ativamente da dinâmica e responderam de forma bem significativa, reconhecendo suas qualidades e revelando-se por meio da auto-avaliação. Desse dia em diante, eles passaram a ser outras crianças, muito mais responsáveis, atenciosas e mais ativas.

As experiências fortaleceram o papel de educador como facilitador de aprendizagem, aberto às novas experiências, procurando compreender, numa relação empática, também os sentimentos $e$ os problemas dos alunos $e$ tentando estimulá-los à auto-realização.

Com a intenção, de enfatizar a relevância do trabalho de estimular a auto-estima e o autoconhecimento, bem como falar sobre si, procurou-se estabelecer o reconhecimento de valores já existentes e, ao mesmo tempo, fortalecendo-os como fonte de enriquecimento moral.

A Proposta Curricular de Santa Catarina (1998, p. 240) enfatiza:
Respeitar e valorizar as diferenças não significa aderir os valores do outro, mas respeitá-los como expressão da diversidade, respeito que é, em si, devido a todo ser humano, por sua dignidade intrínseca sem qualquer discriminação.

Dentro deste contexto, um momento particularmente significativo dentro das atividades de extensão foi o trabalho realizado com crianças de três a quatro anos de idade, quando confeccionaram fantoches por meio de dobraduras e sucatas com rolos de papel higiênico, escolhendo uma das personagens da fábula contada. Foi impressionante como elas ficaram absortas neste momento, pois tiveram contato com diversos materiais de pintura, como giz de cera, lápis de cor, canetas coloridas e guache. Dois aspectos a serem ressaltados: 0 primeiro é a capacidade de observação e atenção a detalhes na confecção dos animais e a relação destes com o mundo: suas necessidades vitais, habitat, alimentação, diferentes espécies, entre outros; o segundo, a fascinação ao conseguir realizar o trabalho. A contação da fábula realmente traz consigo a fantasia e a imaginação que permitem e possibilitam o despertar de processos criativos.

No encontro com a literatura (ou com a Arte em geral) os homens têm a oportunidade de ampliar, transformar ou enriquecer sua própria experiência de vida, em um grau de intensidade não igualada por nenhuma outra atividade. (COELHO, 2000, p. 25)

O fato citado evidenciou a utilização de histórias, que é também arte, combinada com outras disciplinas do currículo, pode significar um grande avanço na promoção e valorização da expressão dos educandos, embora em certos momentos possam sentir-se inseguros, mas que 
apoiados no professor soltam-se e apresentam um desempenho excelente.

Este aspecto também foi contemplado em outra situação de aprendizagem, com a contação da fábula A menina do leite. As crianças colaboraram na caracterização do personagem, e foi a partir daí que a curiosidade tomou conta dos demais alunos. Na verdade, a fábula foi apresentada para os alunos por meio de dramatização. Neste momento, os alunos ficaram atentos para compreender a moral da fábula. Até um aluno que muitas vezes era distraído nas aulas ficou concentrado e surpreso, falou que adorou a maneira que a fábula foi contada para eles. Segundo Abramovich (2005, p. 17):

Ler histórias para crianças sempre, sempre... É poder sorrir, rir, gargalhar com situações vividas pelas personagens, com a idéia do conto ou com o jeito de escrever dum autor e, então, poder ser um pouco cúmplice desse momento de humor, de brincadeira, de divertimento...

Este momento foi muito produtivo, cada aluno teve a oportunidade de comentar com seus amigos qual seria o seu maior sonho na vida e foram incríveis as respostas. Muitos dos meninos responderam que queriam ser jogadores de futebol, corredores de rally e até servir ao exército, enquanto as meninas seriam modelos, cantoras, médicas e professoras. Um dos alunos surpreendeu a turma quando falou que para fazer uma faculdade é preciso estudar muito e nem pensar em reprovar.

É de fundamental importância que o aluno tenha a oportunidade de decidir, debater, opinar, de construir sua autonomia e de tornar-se um cidadão crítico e reflexivo na sociedade.

Com o intuito de que cada criança reconhecesse o próprio valor, foi realizada a atividade Leilão. Promoveu-se um leilão de qualidades e valores extraídos de uma caixinha, colocando-as em oferta. Cada criança recebeu uma quantia de cem reais, em xerox, para participar da brincadeira. Os alunos julgavam a importância das qualidades, valores e faziam suas ofertas, adquirindo-a o que maior oferta fizesse. Foram leiloados valores, qualidades como: tolerância, cooperação, felicidade, generosidade, religião, solidariedade, responsabilidade, respeito, união, saúde, amizade, amor, escola, férias, família, trabalho, honestidade, compreensão, esperança, carinho. Após todos os valores serem colocados à venda, houve um espaço para reflexão sobre a hierarquia dos valores de cada um, sendo que doze alunos ofertaram cem reais para a saúde, amizade, amor, união, compreensão, honestidade, trabalho, família, férias, carinho, escola, esperança. Os demais valores, como a solidariedade foi ofertada por noventa e seis reais, o respeito por noventa e cinco, a responsabilidade oitenta e seis, a generosidade e a felicidade, oitenta, a religião, setenta, tolerância, sessenta e finalmente a cooperação por cinqüenta reais. Cada criança distribuía seu afeto e interesse pelos valores a serem leiloados.

Em uma folha sulfite fizeram uma distribuição de como usariam seus cem reais na hierarquia de dez valores mais e menos importantes em suas vidas pessoais. Foi muito interessante. Escolheram valores significativos e atribuíram valores merecedores. Conforme Sampaio (2004, p. 99):

A educação para os valores humanos transforma a educação em instrumento efetivo para a realização do homem na conquista da paz, das relações, da liberdade criativa e da busca da perfeição. Desse modo, permite que a síntese cultural e espiritual da humanidade seja compartilhada sem barreiras, formando um alicerce comum, sobre o qual se constroem as relações em benefício mútuo. 
E, por último, cada grupo recebeu materiais como: cartolina, caneta, giz de cera, lápis de cor e selecionaram dez valores considerados mais importantes para a confecção dos gráficos.

As crianças participaram com entusiasmo de todo o processo e demonstraram nitidamente sua satisfação ao concluírem suas atividades. Percebeu-se de fato, e concretamente, a necessidade que os alunos têm de vivenciar situações em que o sentimento $e$ a emoção tenham espaço para serem expressos. Segundo Sampaio (2004, p. 53):

A educação emocional ajuda a abrir o coração na medida em que contribui para processar os bloqueios internos, os vínculos parentais, os traumas ligados ao relacionamento humano, permitindo o fluir da energia, abrindo espaço para a compreensão das conseqüências que as emoções e sentimentos provocam em si mesmo e no outro.

Toda essa experiência foi muito gratificante e de enorme valor. As crianças obtiveram o máximo de conhecimento, conseguiram relacionar com a própria vida os contextos diversos apresentados em cada fábula, a importância de cultivar os valores para a construção de uma sociedade mais justa e humana.

É de suma importância para o aluno essa convivência com o mundo das fábulas, pois cada uma revelará ao leitor uma faceta de transformar ou enriquecer sua própria experiência de vida. E é a partir daí que o professor assume uma responsabilidade maior com a verdade, não em dar a verdade pronta, mas abrir oportunidades para o encontro dela, guiando e deixando o aluno livre para pensar. Dentro dessa perspectiva, a fábula assume um papel relevante à medida em que pode se tornar a principal mediadora em auxiliar a abordar os problemas universais e do cotidiano das crianças, conscientizando-as que os valores não estão ultrapassados, mas continuam sendo fundamentais no comprometimento com uma sociedade justa e humana.

A avaliação que se fez da experiência empreendida até aqui foi altamente positiva. Todo educador é considerado também um aprendiz, portanto, se revela a importância de valorizar toda a ação pedagógica, realizada com dinâmicas diversificadas e contextualizadas no cotidiano escolar; só se constrói novos conhecimentos a partir do momento em que vamos buscá-los.

O educador tem, portanto, uma grande influência na vida do educando, sua ação não se limita a ensinar, mas em despertar a consciência, promover a liberdade, tornando-se formador de personalidade. Sua tarefa vai além do desenvolvimento do raciocínio lógico formal do aluno, mas também observar e contemplar, indagar e refletir sobre todo o processo da vida com as crianças.

Possibilitar ao aluno viver novas experiências, expressar seus sentimentos, pensamentos e emoções livremente é oportunizálo ao acesso a novas informações, tendo como instrumento a construção e resgate de valores humanos, que permitem à criança identificá-los como ser cognoscente que é.

A compreensão da fábula é uma forma de tratar certas atitudes humanas, como a disputa entre fortes e fracos, a esperteza, a ganância, a gratidão, o ser bondoso, fatores imprescindíveis na compreensão de certos valores pelas crianças, valores de conduta humana ou convívio social.

O educador pode construir e resgatar os valores humanos com seus alunos, no sentido da moral transmitida, compreendendo os aspectos positivos e negativos que as fábulas podem conter.

A proposta desenvolvida demonstrou que a intervenção deve ocorrer no processo de ensino aprendizagem, para não se tornar uma rotina cansativa e sem contextualização. Tais 
aspectos são fundamentais na busca da qualidade da educação. Qualidade esta que não depende apenas do acúmulo de informações, mas, sobretudo, da postura ética dos professores.

O educando traz consigo uma história e diferentes modos de vida e de experiências culturais que devem ser valorizados no seu processo de desenvolvimento.

Por estas razões, o trabalho realizado, a intervenção do projeto de extensão na prática educativa, evidenciou o quanto se pode aprofundar e enriquecer a vida na escola e comunidades, subsidiando momentos virtuosos. A busca de incorporar valores para que a educação seja realmente a arte de conhecer, cuidar e criar.

Dentro deste contexto, a brincadeira oferece a oportunidade de tornar estas crianças mais humanas, dando-lhes oportunidade de serem elas mesmas, quando se expressam livremente, transformam-se, curam suas angús-

\section{REFERÊNCIAS}

ABRAMOVICH, Fanny. Literatura infantil: gostosuras e bobices. São Paulo: Scipione, 2005 (Pensamento e ação no Magistério).

ASSMANN, Hugo. Reencantar a educação: rumo à sociedade aprendente. Petrópolis: Vozes, 2000.

CAGNETI, Sueli; WERNER. Livro que te quero livre. São Paulo: Letras Brasileiras, 2005. tias, aprendem e crescem. O brincar surge como o momento certo para resgatar nossos valores enquanto seres humanos, seja na relação entre as várias gerações, nos vários contextos sócioculturais-econômicos.

Embora o tema não apresente uma contribuição inovadora, o que se pretende é focar numa educação que possa deixar nossas crianças e jovens imbuídos na busca da realização intra e interpessoal, no respeito e na solidariedade. Requer persistência nas mais diferenciadas atividades, por parte de nossas escolas e mestres. $\mathrm{O}$ amor não pode ser negligenciado, mas alimentado de alegrias, sendo alicerce seguro para um futuro melhor. É a ação que fará a diferença. A possibilidade saudável de conviver com o outro: aprender a ganhar e perder, aprender a ouvir e a falar, aprender a questionar e a respeitar normas sociais, e a enfrentar desafios, propiciam a escolher livremente o caminho para a autonomia.

COELHO, Nelly Novaes. Literatura infantil: teoria, análise, didática. São Paulo: Moderna, 2000.

SAMPAIO, Dulce Moreira. A pedagogia do ser: educação dos sentimentos e dos valores humanos. Petrópolis: Vozes, 2004.

SANTA CATARINA. Secretaria de Educação Cultura e Desporto. Proposta Curricular de Santa Catarina. MEC,1998.

Texto recebido em 20 fev. 2008

Texto aprovado em 28 mar. 2008 